\title{
Motivation for smoking cessation among drug-using smokers under methadone maintenance treatment in Vietnam
}

Bach Xuan Tran ${ }^{1,2^{*}{ }^{+}}$, Long Hoang Nguyen ${ }^{3+}$, Huyen Phuc Do ${ }^{4}$, Nhung Phuong Thi Nguyen ${ }^{5}$, Huong Thu Thi Phan ${ }^{6}$, Michael Dunne $e^{4}$ and Carl Latkin ${ }^{2}$

\begin{abstract}
Background: Smoking cessation treatment service is concerned to be a critical element in methadone maintenance treatment (MMT) in order to diminish the effect of smoke on health outcomes. To implement the smoking cessation services in Vietnam, we examined the stages of change to quit and determined associated factors among MMT patients.

Methods: We conducted a cross-sectional survey with 1016 MMT patients in five clinics in Hanoi and Nam Dinh province, of those, 932 (91.7\%) were ever-smokers. Patients were classified into four groups: "pre-contemplation," "contemplation," "preparation," and "action and maintenance" by using the transtheoretical model. Multivariate logistic regression was applied to determine the associated factor for intention and action to quit smoking.

Results: Overall, $96 \%$ were not actively trying to quit or maintain abstinence. Age older than 45, HIV-positive status, and residence in Hanoi were negatively associated with intention to quit. Meanwhile, higher levels of nicotine dependence and number of years of smoking negatively associated with quitting and abstinence.

Conclusions: The study indicated the high rate of MMT smokers being in pre-contemplation stage but low proportion of quitting and maintaining abstinence. It emphasizes the importance of availability and accessibility of information about smoking cessation therapies and services. Integrating cessation programs into health-care services should be considered to provide tailored interventions for different patient groups.
\end{abstract}

Keywords: Smoking, Cessation, Stage, Change, Methadone, MMT, Drug use, Vietnam

\section{Background}

Improving health status and supporting healthy behaviors are the goals of interventions for people who inject drugs (PWID) [1]. As a country experienced a rapid spread of HIV infection in drug-using populations, Vietnam has been implementing a comprehensive harm reduction strategy [2]. First introduced in 2008, methadone maintenance treatment (MMT) service has become an essential component of the National HIV/AIDS Strategy [2]. Previous studies have shown that MMT is costeffective in preventing new HIV cases, improving HIV/

\footnotetext{
* Correspondence: bach@hmu.edu.vn

${ }^{\dagger}$ Equal contributors

'Institute for Preventive Medicine and Public Health, Hanoi Medical University, Hanoi, Vietnam

${ }^{2}$ Johns Hopkins Bloomberg School of Public Health, Baltimore, MD, USA Full list of author information is available at the end of the article
}

AIDS treatment outcomes, and relieving the economic burden of HIV/AIDS and substance abuse on both health systems and affected households [3-5]. MMT, therefore, is the primary intervention that engages IDU into harm reduction programs and health-care services.

Although drug-use behaviors significantly changed over the course of MMT, other unhealthy behaviors may result in diminished health status and quality of life in this patient group [6]. Despite decreasing prevalence of smoking in general population (56\%), it remains high among MMT patients (from 71 to $98 \%$ ) [7-10]. In developed countries, some MMT programs have instituted smoking bans, which has reduced the proportion of staff who smoke but not proportion of patients [11]. Evidence showed that an interaction between methadone and nicotine might increase euphoria and diminish mental 
problems such as restlessness, irritability, and depression [12], by which maintains smoking and reduces patients' attempts to quit [7]. This interaction is considered a major cause of morbidity, mortality, disability, and poorer quality of life among opioid-dependent smokers compared to non-smokers [13-15]. Therefore, attention should be paid on smoking among PWID, and cessation interventions should be encouraged during MMT [15-18].

Understanding motivation to quit smoking may help predict success of cessation $[19,20]$. This is more important among drug users who reported much lower success rate in quitting smoking $(12-22 \%)$ than general population (48-58 \%) [7-9, 21-23]. Previous studies have shown a number of individuals and environmental factors that influence the process of adapting and maintaining smoking abstinence among PWID. These factors included socioeconomic status, mental health problems, unavailability of health services, family supports, peer influences, and cultural acceptability [23, 24]. Given its high variation across settings, empirical evidence of contextual factors are necessary to design effective smoking cessation programs for PWID.

The rapid expansion of MMT services in Vietnam has provided the treatment to over 30,000 patients $[25,26]$. Although the prevalence of smoking among men in Vietnam was high, however, understanding of smoking and motivation to quit among MMT patients are still limited. In this study, we sought to assess patients' motivation to quit smoking and its associated factors over the course of MMT in a multi-site survey.

\section{Methods}

\section{Study design and sampling technique}

A cross-sectional survey was conducted during January to August 2013 in two northern provinces: Hanoi and Nam Dinh. Five MMT clinics were purposely selected including (1) provincial and district sites, (2) in both rural and urban areas, and (3) different integrative models (Table 1). We invited all patients who registered for MMT at the selected sites to participate in the survey. Eligibility criteria for recruiting participants included (1) taking or initiating MMT in selected sites, (2) presenting at clinics during study period, (3) being 18 years old or above, (4) having capacity to answer questionnaire, and (5) agreeing to participate. A total of 1016 patients $(91.5 \%$ response rate) were interviewed, of those, 932 (91.7 \%) reported ever smoked that formed the subgroup of this analysis. In a designated room, face-to-face interviews were carried out by well-trained investigators using a structured questionnaire for about $30 \mathrm{~min}$.

\section{Measurements}

Variables of interest were selected by adopting the sociocontextual model of Sorensen et al. for reducing tobacco use among blue-collar workers [27]. In this study, we measured the influence of patient- and provider-related factors on motivation and readiness to quit smoking among MMT patients.

\section{Socioeconomic status}

Socioeconomic factors including age, gender, marital status, education, occupation, religion, and income were investigated. Income per month per capita was computed by summing all monthly income sources of household, then dividing to the number of household's members.

\section{Health-related quality of life}

Health status was measured using EQ-5D-5L instrument which showed good measurement properties in Vietnamese settings [28]. EQ-5D-5L contains five dimensions (mobility, self-care, usual activities, pain/discomfort, and anxiety/depression) with five response levels [29]. In addition, body mass index and HIV status were recorded.

\section{Health-care and MMT service utilization}

The use of inpatient and outpatient health services over the past 12 months and duration on MMT were self-reported.

\section{Substance abuse}

To assess alcohol use, we employed a brief version of the alcohol use disorders identification test-consumption (AUDIT-C) instrument [30]. The Vietnamese version has been used in previous studies [31, 32]. It is comprised of questions with a total score of $0-10$. Higher scores indicate higher risks of alcohol dependence. Hazardous

Table 1 Study settings and sample size

\begin{tabular}{lllll}
\hline Level & Settings & Site Name & Type of services & Sample size \\
\hline District (rural) & Nam Dinh City & Provincial AIDS Centre (PAC) & MMT + VCT & 248 \\
District (rural) & Xuan Truong District & District Health Centre (DHC) & MMT + VCT + ART + GH & 128 \\
District (urban) & Tu Liem District & District Health Centre & MMT + VCT + ART + GH & 161 \\
District (urban) & Long Bien District & District Health Centre & MMT + VCT + ART + GH & 170 \\
District (urban) & Ha Dong District & Regional Polyclinic (RPC) & MMT + GH & 196 \\
\hline
\end{tabular}

VCT voluntary HIV testing and counseling, $A R T$ antiretroviral treatment, $G H$ general healthcare 
drinkers are identified with the threshold of 4 or above for men and 3 or above for women [30,33]. Additionally, binge drinkers are determined if the respondents have any positive response to the third question. Illicit drug use behaviors included history and current opioid use, duration of drug use, and the experience of previous drug treatment.

\section{Smoking-related characteristics}

To understand the motivation to quit smoking of MMT patients, we applied the transtheoretical model that describes the progressing of health behaviors through a series of five sequential stages of change. This includes (1) pre-contemplation $\rightarrow(2) \quad$ contemplation $\rightarrow$ (3) preparation $\rightarrow$ (4) action $\rightarrow$ (5) maintenance. We asked the patients a question: "Are you thinking about quitting smoking?" with four response levels: "No thought of quitting," "Think I should quit but not quite ready," "Starting to think about how to change my smoking behavior," and "Take action to quit" corresponding to the stages of $(1) \rightarrow(4)$. The stage (5) maintenance included those who have been abstinent of smoking over 6 months.

In addition, the Fagerström test for nicotine dependence (FTND) was used to assess the levels of nicotine dependence among patients. This instrument contains six items that yield a total score of $0-10$. Higher score indicates higher level of dependence [34]. Based on the score, patients were classified into following groups: $0-2$ : very low, 3-4: low, 5 : moderate, $6-7$ : high, and $8-10$ : very high. Other indicators, including smoking duration, expenses, and number of cigarettes per days, were also recorded. In addition, we asked patients who thought of quitting or cutting down the number of cigarettes they smoke what measures or supports they would like to receive to take action and maintain abstinence.

\section{Data analysis}

The $p$ value $<0.05$ was considered statistically significance. $T$ test, ANOVA test, and $\chi[2]$ were used to measure the difference between means and proportions. To identify the determinants of intention and taking action to quit smoking, we employed multivariate binominal logistic regression, with fractional polynomial model for duration of MMT treatment, to assess the non-linear relationships among variables. In addition, backward stepwise model was approached to include variables with the threshold of $p$ values of $\log$-likelihood ratio test $<0.2$. We then displayed the results by odd ratios (OR) with corresponding $95 \%$ CI. Data analysis was performed by using STATA software version 12.0 (Stata Corp. LP, College Station, United States of America).

\section{Ethical approval}

This study was approved by the Vietnam Authority of HIV/AIDS Control's Scientific Research Committee.
Written informed consents were collected before starting the interview. Respondents could withdraw from the study at any time. The information of patients was coded to ensure confidentiality.

\section{Results}

Of 932 respondents, the mean age of sample was 36.5 years $(\mathrm{SD}=7.4)$. The predominant groups were male $(98.8 \%)$, with a religious orientation of cult of ancestors $(88.7 \%)$, and living with spouse/partner (66.7 \%). Most of the respondents attained less than high school (54.3\%) and had employment (74.3\%). The majority of the participants had income more than 2.5 million VND per month (43.6\%) (Table 2). Table 2 also shows the health status and health-care utilization of patients. There were $7.9 \%$ of respondents who were HIV-positive and $6.3 \%$ currently taking ART medication. Based on the EQ-5D-5L, about one fifth of sample reported anxiety/ depression (20.2 \%) and $17.1 \%$ felt pain/discomfort. About $22 \%$ had used outpatient health-care service in the last 12 months, while $8.3 \%$ used inpatient services.

Table 3 indicates substance-use behaviors among MMT patients. More than a half of respondents smoked over 10 cigarettes per day. The proportions of people smoking within 5 min of waking and even if sick in bed were 32.8 and $0.9 \%$, respectively. About half of respondents reported a moderate to very high levels of nicotine dependence. The mean age of initial smoking were 17.2 $(\mathrm{SD}=3.5)$, and the mean duration of smoking was 14.1 years $(\mathrm{SD}=8.5)$. On average, participants spent 300 thousand Vietnam dong ( USD 15, 2013 exchange rate) monthly for tobacco.

Table 3 also shows that the mean age of initial drug use was 24.4 years $(\mathrm{SD}=6.5)$. There were $74.7 \%$ respondents ever injected drug, and $4.8 \%$ of patients were concurrently using opiates during MMT. Most of the samples had one to five episodes of drug rehabilitation $(66.0 \%)$. As for alcohol use, the prevalence of hazard and binge drinking was 57.1 and $53.5 \%$, respectively.

There was only $4 \%$ currently taking actions to quit smoking, meanwhile $22.1 \%$ were in preparation stage and $22.8 \%$ were in contemplation stage where they thought of quitting. In Table 4, preference for cessation supports were explored among those who were aware of the harms of smoking $(n=455)$. Of 423 responses (93\%), self-administration without others' supports was the most preferable approach for smoking cessation among MMT smokers (77.6 \%), followed by using nicotine replacement therapy (11.3\%) and having familial (5\%) and health workers' (4.5\%) supports.

Results from reduced multivariate logistic regression are shown in Table 5. The intention to quit smoking of MMT patients was negatively associated with age older than 45, HIV-positive status, and residence in Hanoi, 
Table 2 Demographic, health status, and health-care utilization of respondents

\begin{tabular}{|c|c|c|c|c|c|c|c|c|c|c|c|}
\hline & \multicolumn{2}{|c|}{ Pre-contemplation } & \multicolumn{2}{|c|}{ Contemplation } & \multicolumn{2}{|c|}{ Preparation } & \multicolumn{2}{|c|}{ Action and Maintenance } & \multicolumn{2}{|l|}{ Total } & \multirow[t]{2}{*}{$p$} \\
\hline & $n$ & $\%$ & $n$ & $\%$ & $n$ & $\%$ & $n$ & $\%$ & $n$ & $\%$ & \\
\hline \multirow[t]{2}{*}{ Total } & 477 & 51.2 & 212 & 22.8 & 206 & 22.1 & 37 & 4.0 & 932 & 100.0 & \\
\hline & Mean & SD & Mean & SD & Mean & SD & Mean & SD & Mean & SD & \\
\hline Age & 37.0 & 7.7 & 36.1 & 7.3 & 36.0 & 6.7 & 35.3 & 7.0 & 36.5 & 7.4 & 0.19 \\
\hline Sex (male) & 473 & 99.2 & 212 & 100.0 & 202 & 98.1 & 34 & 91.9 & 921 & 98.8 & $<0.01$ \\
\hline \multicolumn{12}{|l|}{ Marital status } \\
\hline Single/divorced/widow & 160 & 33.5 & 61 & 28.8 & 78 & 37.9 & 11 & 29.7 & 310 & 33.3 & 0.25 \\
\hline Live with spouse/partner & 317 & 66.5 & 151 & 71.2 & 128 & 62.1 & 26 & 70.3 & 622 & 66.7 & \\
\hline \multicolumn{12}{|l|}{ Educational attainment } \\
\hline$<$ High school & 277 & 58.1 & 114 & 54.0 & 91 & 44.4 & 23 & 62.2 & 505 & 54.3 & $<0.01$ \\
\hline High school & 177 & 37.1 & 85 & 40.3 & 90 & 43.9 & 12 & 32.4 & 364 & 39.1 & \\
\hline$>$ High school & 23 & 4.8 & 12 & 5.7 & 24 & 11.7 & 2 & 5.4 & 61 & 6.6 & \\
\hline \multicolumn{12}{|l|}{ Employment } \\
\hline Unemployed & 131 & 27.5 & 59 & 27.8 & 39 & 18.9 & 11 & 29.7 & 240 & 25.8 & 0.09 \\
\hline Currently working & 346 & 72.5 & 153 & 72.2 & 167 & 81.1 & 26 & 70.3 & 692 & 74.3 & \\
\hline \multicolumn{12}{|l|}{ Religion } \\
\hline Cult of ancestors & 428 & 89.7 & 188 & 88.7 & 180 & 87.4 & 31 & 83.8 & 827 & 88.7 & 0.62 \\
\hline Others & 49 & 10.3 & 24 & 11.3 & 26 & 12.6 & 6 & 16.2 & 105 & 11.3 & \\
\hline \multicolumn{12}{|l|}{ Income per capita } \\
\hline$<1.2$ million VND & 101 & 21.2 & 48 & 22.6 & 38 & 18.5 & 7 & 18.9 & 194 & 20.8 & 0.55 \\
\hline 1.2-2.5 million VND & 160 & 33.5 & 72 & 34.0 & 86 & 41.8 & 14 & 37.8 & 332 & 35.6 & \\
\hline$>2.5$ million VND & 216 & 45.3 & 92 & 43.4 & 82 & 39.8 & 16 & 43.2 & 406 & 43.6 & \\
\hline \multicolumn{12}{|l|}{ Location } \\
\hline Nam Dinh & 313 & 65.6 & 117 & 55.2 & 104 & 50.5 & 14 & 37.8 & 548 & 58.8 & $<0.01$ \\
\hline Hanoi & 164 & 34.4 & 95 & 44.8 & 102 & 49.5 & 23 & 62.2 & 384 & 41.2 & \\
\hline \multicolumn{12}{|l|}{ Area of clinics } \\
\hline Rural & 60 & 12.6 & 32 & 15.1 & 31 & 15.1 & 8 & 21.6 & 131 & 14.1 & 0.40 \\
\hline Urban & 417 & 87.4 & 180 & 84.9 & 175 & 85.0 & 29 & 78.4 & 801 & 85.9 & \\
\hline \multicolumn{12}{|l|}{ MMT model } \\
\hline $\mathrm{MMT}+\mathrm{VCT}$ & 104 & 21.8 & 63 & 29.7 & 71 & 34.5 & 15 & 40.5 & 253 & 27.2 & $<0.01$ \\
\hline $\mathrm{MMT}+\mathrm{GH}$ & 111 & 23.3 & 34 & 16.0 & 50 & 24.3 & 5 & 13.5 & 200 & 21.5 & \\
\hline $\mathrm{MMT}+\mathrm{VCT}+\mathrm{GH}+\mathrm{ART}$ & 262 & 54.9 & 115 & 54.3 & 85 & 41.3 & 17 & 46.0 & 479 & 51.4 & \\
\hline \multicolumn{12}{|l|}{ Health-related status } \\
\hline \multicolumn{12}{|l|}{ Body mass index } \\
\hline Normal weight & 366 & 76.7 & 151 & 71.2 & 152 & 73.8 & 28 & 75.7 & 697 & 74.8 & 0.57 \\
\hline Underweight & 28 & 5.9 & 19 & 9.0 & 13 & 6.3 & 4 & 10.8 & 64 & 6.9 & \\
\hline Overweight, obesity & 83 & 17.4 & 42 & 19.8 & 41 & 19.9 & 5 & 13.5 & 171 & 18.4 & \\
\hline HIV-positive & 47 & 9.9 & 10 & 4.7 & 12 & 5.8 & 5 & 13.5 & 74 & 7.9 & 0.04 \\
\hline Current taking ART & 36 & 7.6 & 9 & 4.3 & 10 & 4.9 & 4 & 10.8 & 59 & 6.3 & 0.42 \\
\hline Currently feeling pain & 83 & 17.4 & 32 & 15.1 & 40 & 19.4 & 4 & 10.8 & 159 & 17.1 & 0.49 \\
\hline Currently feeling anxiety/depression & 89 & 18.7 & 35 & 16.5 & 57 & 27.7 & 7 & 18.9 & 188 & 20.2 & 0.02 \\
\hline \multicolumn{12}{|c|}{ Health-care services utilization in the last 12 month } \\
\hline Outpatient service utilization & 85 & 17.8 & 57 & 26.9 & 53 & 25.7 & 11 & 29.7 & 206 & 22.1 & 0.01 \\
\hline Inpatient service utilization & 43 & 9.0 & 19 & 9.0 & 14 & 6.8 & 1 & 2.7 & 77 & 8.3 & 0.46 \\
\hline
\end{tabular}


Table 3 Smoking, nicotine dependence and other substance abuse

\begin{tabular}{|c|c|c|c|c|c|c|c|c|c|c|c|}
\hline & \multicolumn{2}{|c|}{$\begin{array}{l}\text { Pre- } \\
\text { contemplation }\end{array}$} & \multicolumn{2}{|c|}{ Contemplation } & \multicolumn{2}{|c|}{ Preparation } & \multicolumn{2}{|c|}{$\begin{array}{l}\text { Action and } \\
\text { maintenance }\end{array}$} & \multicolumn{2}{|l|}{ Total } & \multirow[t]{2}{*}{$p$} \\
\hline & $\bar{n}$ & $\%$ & $\bar{n}$ & $\%$ & $n$ & $\%$ & $\bar{n}$ & $\%$ & $\bar{n}$ & $\%$ & \\
\hline \multicolumn{12}{|l|}{ Smoking } \\
\hline \multicolumn{12}{|l|}{ Number of cigarettes per day } \\
\hline$\leq 10$ & 215 & 46.9 & 101 & 47.6 & 85 & 41.7 & 13 & 59.1 & 414 & 46.2 & \multirow[t]{4}{*}{0.64} \\
\hline$\geq 11-20$ & 206 & 45.0 & 99 & 46.7 & 98 & 48.0 & 8 & 36.4 & 411 & 45.9 & \\
\hline $21-30$ & 24 & 5.2 & 8 & 3.8 & 16 & 7.8 & 1 & 4.6 & 49 & 5.5 & \\
\hline$>30$ & 13 & 2.8 & 4 & 1.9 & 5 & 2.5 & 0 & 0.0 & 22 & 2.5 & \\
\hline Smoke within 5 min of waking & 156 & 33.7 & 57 & 27.0 & 79 & 38.4 & 9 & 24.3 & 301 & 32.8 & 0.13 \\
\hline Smoke even if sick in bed & 146 & 32.3 & 68 & 32.7 & 57 & 28.1 & 7 & 19.4 & 278 & 30.9 & 0.30 \\
\hline \multicolumn{12}{|l|}{ Nicotine dependence level } \\
\hline Very low & 129 & 27.0 & 64 & 30.2 & 49 & 23.8 & 21 & 56.8 & 263 & 28.2 & \multirow[t]{6}{*}{$<0.01$} \\
\hline Low & 130 & 27.3 & 51 & 24.1 & 58 & 28.2 & 7 & 18.9 & 246 & 26.4 & \\
\hline Moderate & 65 & 13.6 & 29 & 13.7 & 23 & 11.2 & 2 & 5.4 & 119 & 12.8 & \\
\hline High & 93 & 19.5 & 53 & 25.0 & 36 & 17.5 & 5 & 13.5 & 187 & 20.1 & \\
\hline \multirow[t]{2}{*}{ Very high } & 60 & 12.6 & 15 & 7.1 & 40 & 19.4 & 2 & 5.4 & 117 & 12.6 & \\
\hline & Mean & SD & Mean & SD & Mean & SD & Mean & SD & Mean & SD & \\
\hline Age at smoking initiation & 17.02 & 3.4 & 17.05 & 3.7 & 17.87 & 3.4 & 17.49 & 2.9 & 17.24 & 3.5 & 0.02 \\
\hline Duration of regular smoking in years & 14.41 & 8.9 & 13.15 & 8.3 & 14.88 & 7.7 & 10.49 & 7.6 & 14.07 & 8.5 & $<0.01$ \\
\hline Expense for smoking (thousand VND per month) & 302.26 & 312.5 & 289.59 & 272.5 & 310.03 & 259.1 & 140.59 & 185.2 & 294.68 & 289.6 & $<0.01$ \\
\hline FTND score & 4.36 & 2.5 & 4.22 & 2.3 & 4.67 & 2.6 & 2.89 & 2.5 & 4.34 & 2.5 & $<0.01$ \\
\hline \multicolumn{12}{|l|}{ Drug use } \\
\hline Ever inject drug & 369 & 77.4 & 143 & 67.5 & 160 & 77.7 & 24 & 64.9 & 696 & 74.7 & 0.02 \\
\hline Current drug use & 24 & 5.0 & 8 & 3.8 & 12 & 5.8 & 1 & 2.7 & 45 & 4.8 & 0.71 \\
\hline \multicolumn{12}{|l|}{ \# drug rehabilitation } \\
\hline None & 35 & 7.3 & 17 & 8.0 & 15 & 7.3 & 2 & 5.4 & 69 & 7.4 & 0.71 \\
\hline $1-5$ episodes & 307 & 64.4 & 147 & 69.3 & 133 & 64.6 & 28 & 75.7 & 615 & 66.0 & \\
\hline $6-10$ & 108 & 22.6 & 36 & 17.0 & 47 & 22.8 & 4 & 10.8 & 195 & 20.9 & \\
\hline \multirow[t]{2}{*}{$>10$} & 27 & 5.7 & 12 & 5.7 & 11 & 5.3 & 3 & 8.1 & 53 & 5.7 & \\
\hline & Mean & SD & Mean & SD & Mean & SD & Mean & SD & Mean & SD & \\
\hline Age at first drug use & 24.49 & 6.6 & 24.18 & 7.0 & 24.32 & 6.1 & 24.24 & 6.0 & 24.37 & 6.5 & 0.95 \\
\hline Age at first drug injection & 27.06 & 7.6 & 26.13 & 6.6 & 26.94 & 7.1 & 25.25 & 5.4 & 26.78 & 7.2 & 0.41 \\
\hline Time since 1st drug use & 13.55 & 5.9 & 12.88 & 5.9 & 12.70 & 5.2 & 12.03 & 5.3 & 13.15 & 5.7 & 0.14 \\
\hline Time since 1st drug injection & 10.40 & 5.0 & 9.99 & 4.9 & 9.69 & 4.8 & 10.00 & 4.0 & 10.14 & 4.9 & 0.46 \\
\hline Duration of MMT (month) & 17.10 & 11.0 & 16.83 & 11.2 & 14.57 & 10.0 & 13.56 & 9.3 & 16.34 & 10.8 & 0.02 \\
\hline \multicolumn{12}{|l|}{ Alcohol use } \\
\hline Hazard Drinking $(n=480)$ & 130 & 56.3 & 72 & 59.0 & 62 & 56.9 & 10 & 55.6 & 274 & 57.1 & 0.97 \\
\hline Binge Drinking $(n=480)$ & 124 & 53.7 & 63 & 51.6 & 59 & 54.1 & 11 & 61.1 & 257 & 53.5 & 0.89 \\
\hline
\end{tabular}

while positively associated with having outpatient health-care services in the last 12 months. As for quitting and maintenance, we found that the level of nicotine dependence and longer years of smoking negatively predicted quitting and maintaining abstinence among MMT patients. In these models, the duration on MMT has been treated as a polynomial factor that showed a negative association between the number of months on MMT and the likelihood of smoking abstinence; however, it was not statistically significant.

\section{Discussion}

This is the first study investigating factors associated with the motivation of MMT patients to quit smoking in 
Table 4 Preference for support among MMT patients who thought of smoking cessation

\begin{tabular}{lll}
\hline Cessation support & Number & Percent \\
\hline Health staff support & 19 & 4.5 \\
Family support & 21 & 5.0 \\
Friend/peer support & 6 & 1.4 \\
Using nicotine replacement therapy & 48 & 11.3 \\
Using herbs & 2 & 0.5 \\
Using acupuncture & 1 & 0.2 \\
Use mobile phone & 1 & 0.2 \\
Self-help & 325 & 76.8 \\
\hline
\end{tabular}

Vietnam. Using the transtheoretical model, we characterized the stages that MMT patients are in with regard to their smoking behaviors. The findings showed a substantial proportion of MMT patients were at the precontemplation stage. They did not have any intention to change their smoking behaviors. It is important to note that intentions to quit and taking action to quit smoking were not improved over the course of MMT.

In this study, $44.9 \%$ respondents were in the contemplation and preparation stages and only $4.0 \%$ took action to quit smoking and maintained abstinence. These figures were lower than previous studies in MMT patients. For example, a study of Nahvi et al. showed that $48 \%$ of MMT smokers were in contemplation stage and $22 \%$ were in preparation stage [9]. Another study of Richter et al. suggested that $46 \%$ of MMT patients were in contemplation stage [35]. Since having an intention to

Table 5 Factors associated with Intention to quit and quitting smoking

\begin{tabular}{|c|c|c|c|c|c|c|}
\hline \multirow[b]{3}{*}{ Province (Hanoi vs Nam Dinh) } & \multicolumn{3}{|c|}{ Intention to quit } & \multicolumn{3}{|c|}{ Quitting smoking } \\
\hline & \multirow{2}{*}{$\begin{array}{l}\mathrm{OR} \\
0.47^{* * *}\end{array}$} & \multicolumn{2}{|c|}{$95 \% \mathrm{Cl}$} & \multirow{2}{*}{$\begin{array}{l}\mathrm{OR} \\
0.50^{*}\end{array}$} & \multicolumn{2}{|c|}{$95 \% \mathrm{Cl}$} \\
\hline & & 0.34 & 0.67 & & 0.23 & 1.08 \\
\hline Location (Urban vs Rural) & 1.44 & 0.90 & 2.31 & & & \\
\hline Duration of MMT (month) & 1.00 & 0.99 & 1.02 & 0.99 & 0.95 & 1.03 \\
\hline Outpatient service use last 12 months (yes vs no) & $1.98^{* * *}$ & 1.44 & 2.72 & & & \\
\hline \# of drug rehabilitation & & & & 1.03 & 0.98 & 1.07 \\
\hline \multicolumn{7}{|l|}{ Religion (vs cult of ancestors) } \\
\hline Buddhism & & & & $2.72^{*}$ & 0.84 & 8.78 \\
\hline \multicolumn{7}{|l|}{ Occupation (vs unemployed) } \\
\hline Other jobs & 1.41 & 0.87 & 2.28 & & & \\
\hline \multicolumn{7}{|l|}{ Age (vs 18-<25) } \\
\hline $35-<40$ & & & & $2.63^{* *}$ & 1.30 & 5.30 \\
\hline$\geq 45$ & $0.51^{* * *}$ & 0.34 & 0.78 & & & \\
\hline \multicolumn{7}{|l|}{ Marital status (vs single) } \\
\hline Live with spouse & 1.23 & 0.91 & 1.67 & & & \\
\hline \multicolumn{7}{|l|}{ Income quintile (vs poorest) } \\
\hline Rich & 0.78 & 0.56 & 1.09 & & & \\
\hline Having pain/discomfort (yes vs no) & & & & 0.41 & 0.12 & 1.43 \\
\hline \multicolumn{7}{|l|}{ HIV status (vs negative) } \\
\hline Positive & $0.58^{* *}$ & 0.34 & 0.99 & & & \\
\hline \multicolumn{7}{|l|}{ Body mass index (vs underweight) } \\
\hline Normal & 1.47 & 0.86 & 2.52 & & & \\
\hline \multicolumn{7}{|l|}{ Level of nicotine dependence (vs very low) } \\
\hline Low & & & & $0.31^{* *}$ & 0.12 & 0.81 \\
\hline Moderate & & & & $0.22^{* *}$ & 0.05 & 0.97 \\
\hline High & & & & $0.37^{* *}$ & 0.13 & 1.04 \\
\hline Very high & & & & $0.22^{* *}$ & 0.05 & 0.99 \\
\hline Year of smoking & & & & $0.95^{* *}$ & 0.91 & 1.00 \\
\hline
\end{tabular}

${ }^{*} p<0.1 ;{ }^{* *} p<0.05 ;{ }^{* * *} p<0.01$ 
quit smoking may predict successful smoking abstinence [36], the low rate of intention to quit smoking in the present study may reflect the lack of smoking cessation interventions and antismoking campaigns targeting this population. For MMT patients, as illicit drug use is highly stigmatized in Vietnam, it is likely that their focus is on opiate absences and do not view cessation of tobacco use as a priority. Moreover, smoking is normative among men in Vietnam with over half of the adult male population currently smoking.

Literatures documented that patients might suffer from withdrawal problems (stress/anxiety or other mental problems) while attempting to quit smoking [37] due to nicotine dependence [38]. In our study, higher level of nicotine dependence and number of years of smoking were negative predictors of patient's abstinence to smoking $[39,40]$. This is similar to findings by John et al. who also suggested that nicotine dependence may increase the number of quit attempt but decrease the likelihood of abstinence [38]. As for preferred supports for smoking cessation, the majority of respondents chose selfadministration while having cessation-related health was very limited. It may be because of the unawareness of smokers and unavailability of smoking cessation services as well as other socioeconomic barriers [41].

Noticeably, the duration of MMT was inversely related to the intention, although this association was not statistical significance. To date, prior studies have not examined this association. Since the duration of MMT treatment was proportionate with the reduction of MMT doses, patients with lower doses of methadone were more likely to report quit intensions [9]. Additional research to investigate the interaction between duration of MMT and MMT doses on readiness to quit smoking is warranted.

This study suggested several implications. First, clinicians should understand MMT patients' stage of change for smoking cessation in order to implement tailored counseling and interventions. They should first ask about smoking in MMT clients, then ask about their interest in quitting. Patients who report no interest should be counseled using motivational interviewing about dangers of smoking and ability for people to quit. Those who express interest should be provided with a brief smoking cessation intervention, the "five A's," including ask, advise, assess, assist, and arrange [42]. These tailored clinical interventions should be coupled with community level interventions [41]. Second, providing smoking cessation treatment by integrating into MMT clinics (on-site program) may encourage the motivation for smoking cessation. Besides, for those smokers taking antiretroviral therapies, intervening on smoking may also improve treatment adherence and outcomes [43]. Finally, capacity of health staffs in terms of screening and counseling should be enhanced by training, which helps to enhance the provision of smoking cessation treatment [41].

The strengths of this study included a large sample of MMT patients in various Vietnamese settings. In addition, we employed several measures (EQ-5D-5L, FTND, AUDIT-C) that showed good measurement properties in these patient groups in Vietnam [3, 28, 31, 32, 44, 45]. Nonetheless, some limitations should be acknowledged. First, causal relationships between motivation to quit and related factors cannot be established due to the crosssectional design. Second, data collection was based on self-reports, which might lead to recall bias. Finally, some psychosocial factors such as methadone dose, self-efficacy, depression, tobacco availability, social norms, and smoking cost data were not collected, suggesting the further research to investigate those factors in order to better understand the mechanism of smoking behaviors and develop appropriate interventions.

\section{Conclusions}

In conclusion, the study indicated the high rate of MMT smokers being in pre-contemplation stage but low proportion of quitting and abstinence. This study also underlined the importance of availability and accessibility of information about smoking cessation therapies with the high-quality consultation and services. Integrating cessation programs into health-care services should be considered to provide tailored interventions for different patient groups.

Competing interests

The authors declare that they have no competing interests.

\section{Authors' contributions}

BXT, HTTP, CL conceived of the study, and participated in its design and implementation and wrote the manuscript. LHN analyzed the data. BXT, LHN, HPD, HTTP, CL, MD helped to draft the manuscript. All authors read and approved the final manuscript.

\section{Acknowledgements}

The authors would like to acknowledge supports by the Vietnam Authority of HIV/AIDS Control for the use of this survey data. There was no funding for this analysis.

\section{Author details}

Institute for Preventive Medicine and Public Health, Hanoi Medical University, Hanoi, Vietnam. ${ }^{2}$ Johns Hopkins Bloomberg School of Public Health, Baltimore, MD, USA. ${ }^{3}$ School of Medicine and Pharmacy, Vietnam National University, Hanoi, Vietnam. ${ }^{4}$ School of Public Health and Social Work, The Queensland University of Technology, Brisbane, Australia. ${ }^{5}$ Hanoi University of Pharmacy, Hanoi, Vietnam. ${ }^{6}$ Authority of HIV/AIDS Control, Ministry of Health, Hanoi, Vietnam.

Received: 8 August 2015 Accepted: 27 October 2015

Published online: 30 October 2015

\section{References}

1. Tran BX, Ohinmaa A, Duong AT, Do NT, Nguyen LT, Nguyen QC, et al. Changes in drug use are associated with health-related quality of life improvements among methadone maintenance patients with HIV/AIDS. Qual Life Res. 2012;21(4):613-23. Epub 2011/07/07. doi: 10.1007/s11136-0119963-y. PubMed PMID: 21732198. 
2. Nguyen TT, Nguyen LT, Pham MD, Vu HH, Mulvey KP. Methadone maintenance therapy in Vietnam: an overview and scaling-up plan. Adv Prev Med. 2012;2012:732484.

3. Tran BX, Nguyen LT. Impact of methadone maintenance on health utility, health care utilization and expenditure in drug users with HIV/AIDS. Int J Drug Policy. 2013;24(6):e105-10.

4. Tran BX. Willingness to pay for methadone maintenance treatment in Vietnamese epicentres of injection-drug-driven HIV infection. Bull World Health Organ. 2013;91(7):475-82.

5. Tran BX, Ohinmaa A, Duong AT, Nguyen LT, Vu PX, Mills S, et al. The costeffectiveness and budget impact of Vietnam's methadone maintenance treatment programme in HIV prevention and treatment among injection drug users. Glob Public Health. 2012;7(10):1080-94. Epub 2012/10/31. doi: 10.1080/17441692.2012.736259. PubMed PMID: 23106230

6. Zirakzadeh A, Shuman C, Stauter E, Hays JT, Ebbert JO. Cigarette smoking in methadone maintained patients: an up-to-date review. Curr Drug Abuse Rev. 2013;6(1):77-84.

7. Richter KP, Hamilton AK, Hall S, Catley D, Cox LS, Grobe J. Patterns of smoking and methadone dose in drug treatment patients. Exp Clin Psychopharmacol. 2007;15(2):144-53.

8. Shadel WG, Stein MD, Anderson BJ, Herman DS, Bishop S, Lassor JA, et al. Correlates of motivation to quit smoking in methadone-maintained smokers enrolled in a smoking cessation trial. Addict Behav. 2005;30(2):295-300. doi: 10.1016/j.addbeh.2004.05.018.

9. Nahvi S, Richter K, Li X, Modali L, Arnsten J. Cigarette smoking and interest in quitting in methadone maintenance patients. Addict Behav. 2006;31(11):2127-34.

10. Organization $\mathbf{W H}$. WHO global report on trends in prevalence of tobacco smoking 2015. Geneva: World Health Organization; 2015.

11. Pagano A, Guydish J, Le T, Tajima B, Passalacqua E, Soto-Nevarez A, et al. Smoking behaviors and attitudes among clients and staff at New York Addiction Treatment Programs following a smoking ban: findings after 5 years. Nicotine Tob Res: Off J Soc Res Nicotine Tob. 2015. Epub 2015/05/28. doi: 10.1093/ntr/ntv116. PubMed PMID: 26014456.

12. Elkader AK, Brands B, Selby P, Sproule BA. Methadone-nicotine interactions in methadone maintenance treatment patients. J Clin Psychopharmacol. 2009;29(3):231-8.

13. Hser YI, McCarthy WJ, Anglin MD. Tobacco use as a distal predictor of mortality among long-term narcotics addicts. Prev Med. 1994;23(1):61-9.

14. Hurt RD, Offord KP, Croghan IT, et al. Mortality following inpatient addictions treatment: role of tobacco use in a community-based cohort. JAMA. 1996;275(14):1097-103. doi: 10.1001/jama.1996.03530380039029.

15. McCarthy WJ, Zhou Y, Hser YI, Collins C. To smoke or not to smoke: impact on disability, quality of life, and illicit drug use in baseline polydrug users. J Addict Dis. 2002;21(2):35-54.

16. Chait LD, Griffiths RR. Effects of methadone on human cigarette smoking and subjective ratings. J Pharmacol Exp Ther. 1984;229(3):636.

17. Frosch DL, Nahom D, Shoptaw S. Optimizing smoking cessation outcomes among the methadone maintained. J Subst Abus Treat. 2002;23(4):425-30.

18. Story J, Stark MJ. Treating cigarette smoking in methadone maintenance clients. J Psychoactive Drugs. 1991;23(2):203-15.

19. Ajzen I, Fishbein M. Understanding attitudes and predicting social behavior. Englewood Cliffs: Prentice-Hall; 1980.

20. Prochaska OJ, Redding AC, Evers KE. The transtheoretical model and stages of change. In: Glanz K, Rimer BK, Viswanath K, editors. Health behavior and health education: theory, research, and practice. 4th ed. San Francisco: Jossey-Bass; 2008. p. 97-117.

21. Shoptaw S, Rotheram-Fuller E, Yang $X$, Frosch DL, Nahom D, Jarvik ME, et al. Smoking cessation in methadone maintenance. Addiction. 2002;97(10):1317. doi: 10.1046/j.1360-0443.2002.00221.x.

22. Richter KP, Gibson CA, Ahluwalia JS, Schmelzle KH. Tobacco use and quit attempts among methadone maintenance clients. Am J Public Health. 2001;91(2):296-9.

23. Wapf V, Schaub M, Klaeusler B, Boesch L, Stohler R, Eich D. The barriers to smoking cessation in Swiss methadone and buprenorphine-maintained patients. Harm Reduction J. 2008;5:10.

24. Twyman L, Bonevski B, Paul C, Bryant J. Perceived barriers to smoking cessation in selected vulnerable groups: a systematic review of the qualitative and quantitative literature. BMJ Open. 2014;4(12), e006414.

25. Control VAoHA. The annual review of HIV/AIDS control and prevention in the first six months 2015 and action plan in the last six months in 2015. Hanoi: Ministry of Health; 2014.
26. control VAoHA. Update the implementation of opioid substance abuse treatment by methadone (Vietnamese). 2015. http://www.vaac.gov.vn/ Desktop.aspx/Cac-hoat-dong-chuyen-mon/Tinh-hinh-dich-so-lieu-HIVAIDS/ Cap_nhat_tinh_hinh_thuc_hien_chi_tieu_dieu_tri_nghien_cac_chat_dang_ thuoc_phien_bang_Methadone_MMT/.

27. Sorensen G, Barbeau E, Hunt MK, Emmons K. Reducing social disparities in tobacco use: a social-contextual model for reducing tobacco use among blue-collar workers. Am J Public Health. 2004;94(2):230-9.

28. Tran BX, Ohinmaa A, Nguyen LT. Quality of life profile and psychometric properties of the EQ-5D-5 L in HIV/AIDS patients. Health Qual Life Outcomes. 2012;10:132.

29. EQOL G. EQ-5D-5L user guide: basic information on how to use the EQ-5D$5 \mathrm{~L}$ instrument. Rotterdam: EQOL G; 2011.

30. Bradley KA, DeBenedetti AF, Volk RJ, Williams EC, Frank D, Kivlahan DR. AUDIT-C as a brief screen for alcohol misuse in primary care. Alcohol Clin Exp Res. 2007;31(7):1208-17.

31. Tran BX, Nguyen N, Ohinmaa A, Duong AT, Nguyen LT, Van Hoang M, et al. Prevalence and correlates of alcohol use disorders during antiretroviral treatment in injection-driven HIV epidemics in Vietnam. Drug Alcohol Depend. 2013;127(1-3):39-44. Epub 2012/07/04. doi: 10.1016/ j.drugalcdep.2012.06.009.

32. Tran BX, Nguyen LT, Do CD, Nguyen QL, Maher RM. Associations between alcohol use disorders and adherence to antiretroviral treatment and quality of life amongst people living with HIV/AIDS. BMC Pub Health. 2014;14(1):27.

33. Bush K, Kivlahan DR, McDonell MB, Fihn SD, Bradley KA. The AUDIT alcohol consumption questions (AUDIT-C): an effective brief screening test for problem drinking. Ambulatory care quality improvement project (ACQUIP). alcohol use disorders identification test. Arch Intern Med. 1998;158(16):1789-95.

34. Heatherton TF, Kozlowski LT, Frecker RC, Fagerstrom KO. The Fagerstrom test for nicotine dependence: a revision of the Fagerstrom tolerance questionnaire. Br J Addict. 1991;86(9):1119-27.

35. Richter KP, Gibson CA, Ahluwalia JS, Schmelzle KH. Tobacco use and quit attempts among methadone maintenance clients. Am J Public Health. 2001;91(2):296-9.

36. DiClemente CC, Prochaska JO, Fairhurst SK, Velicer WF, Velasquez MM, Rossi JS. The process of smoking cessation: an analysis of precontemplation, contemplation, and preparation stages of change. J Consult Clin Psychol. 1991;59(2):295-304.

37. Hughes JR. Effects of abstinence from tobacco: valid symptoms and time course. Nic Tob Res: Off J Soc Res Nic Tob. 2007;9(3):315-27.

38. John U, Meyer C, Hapke U, Rumpf H-J, Schumann A. Nicotine dependence, quit attempts, and quitting among smokers in a regional population sample from a country with a high prevalence of tobacco smoking. Prev Med. 2004;38(3):350-8.

39. Breslau N, Johnson EO, Hiripi E, Kessler R. Nicotine dependence in the United States: prevalence, trends, and smoking persistence. Arch Gen Psychiatry. 2001;58(9):810-6.

40. Breslau N, Johnson EO. Predicting smoking cessation and major depression in nicotine-dependent smokers. Am J Public Health. 2000;90(7):1122-7.

41. Fiore MC, Jaén CR, Baker TB. In: Service USDoHaHSPH, editor. Treating tobacco use and dependence: 2008 update. Rockville: Clinical Practice Guideline; 2008.

42. Puschel K, Thompson B, Coronado G, Huang Y, Gonzalez L, Rivera S Effectiveness of a brief intervention based on the ' $5 A^{\prime}$ ' model for smoking cessation at the primary care level in Santiago, Chile. Health Promot Int. 2008;23(3):240-50.

43. Nguyen NT, Tran BX, Hwang LY, Markham CM, Swartz MD, Vidrine Jl, et al. Effects of cigarette smoking and nicotine dependence on adherence to antiretroviral therapy among HIV-positive patients in Vietnam. AIDS Care Oct. 2015;13:1-6. Epub 2015/10/16. doi: 10.1080/09540121.2015.1090535. PubMed PMID: 26461976.

44. Nguyen NP, Tran BX, Hwang LY, Markham CM, Swartz MD, Phan HT, et al. Prevalence of cigarette smoking and associated factors in a large sample of HIV-positive patients receiving antiretroviral therapy in Vietnam. PLoS One. 2015;10(2), e0118185. Epub 2015/02/28. doi: 10.1371/journal.pone.0118185. PubMed PMID: 25723596; PubMed Central PMCID: PMC4344328.

45. Nguyen NT, Tran BX, Hwang LY, Markham CM, Swartz MD, Vidrine Jl, et al. Motivation to quit smoking among HIV-positive smokers in Vietnam. BMC Pub Health. 2015;15:326. Epub 2015/04/18. doi: 10.1186/s12889-015-1672-y. PubMed PMID: 25885342; PubMed Central PMCID: PMC4392856. 